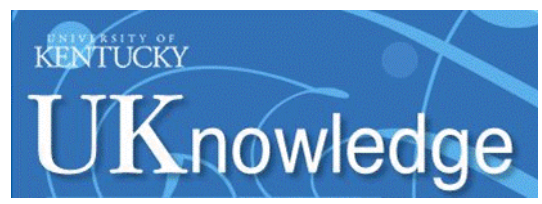

University of Kentucky

UKnowledge

6-2009

\title{
Weight Gain Associated with Hormonal Contraception Use in Adolescents is not Different from Control
}

\author{
Abdel Salous \\ University of Kentucky, abdel.salous@uky.edu \\ Valerie Jones \\ University of Kentucky, valerie.fisher@uky.edu \\ Maria Melguizo Castro \\ University of Kentucky, msmelg2@uky.edu \\ Linah Al-Alem \\ University of Kentucky, linah.al-alem@uky.edu \\ Hatim A. Omar \\ University of Kentucky, hatim.omar@uky.edu
}

Follow this and additional works at: https://uknowledge.uky.edu/pediatrics_facpub

Part of the Pediatrics Commons

Right click to open a feedback form in a new tab to let us know how this document benefits you.

\section{Repository Citation}

Salous, Abdel; Jones, Valerie; Castro, Maria Melguizo; Al-Alem, Linah; and Omar, Hatim A., "Weight Gain Associated with Hormonal Contraception Use in Adolescents is not Different from Control" (2009).

Pediatrics Faculty Publications. 91.

https://uknowledge.uky.edu/pediatrics_facpub/91

This Article is brought to you for free and open access by the Pediatrics at UKnowledge. It has been accepted for inclusion in Pediatrics Faculty Publications by an authorized administrator of UKnowledge. For more information, please contact UKnowledge@lsv.uky.edu. 


\section{Weight Gain Associated with Hormonal Contraception Use in Adolescents is not Different from Control}

Digital Object Identifier (DOI)

http://dx.doi.org/10.1515/IJDHD.2009.8.2.181

Notes/Citation Information

Published in International Journal on Disability and Human Development, v. 8, no. 2, p. 181-185.

(C) Freund Publishing House Limited

The copyright holder has granted permission for posting the article here. 


\title{
Weight gain associated with hormonal contraception use in adolescents is not different from control
}

\author{
Abdel Salous, MSc ${ }^{1}$, Valerie Jones ${ }^{2}$, Maria Melguizo Castro, BSc ${ }^{3}$, Linah Al-Alem, MSc ${ }^{4,5}$ and Hatim A Omar, MD, FAAP \\ ${ }^{\prime} \mathrm{MD} / \mathrm{PhD}$ Program, ${ }^{2}$ Division of Adolescent Medicine, Department of Pediatrics, ${ }^{3}$ Department of Statistics, College of \\ Arts and Sciences, ${ }^{4}$ Department of Molecular and Biomedical Pharmacology, ${ }^{5}$ Department of Obstetrics and \\ Gynecology, University of Kentucky College of Medicine, Lexington, Kentucky, United States of America
}

\begin{abstract}
The use of hormonal contraception is commonly associated with weight gain. The purpose of this retrospective study was to explore the association between the use of hormonal contraception and weight change in an outpatient adolescent patient population in Lexington, Kentucky. Data were gathered from the charts of 259 adolescent female patients seen in an outpatient adolescent clinic for up to 72 months. At the initial visit, all patients were evaluated for risk-taking behavior and received preventive counseling. Patients were categorized as either contraception users or non-users (control group). Contraception users were subdivided into Depot Medroxyprogesterone Acetate (DMPA) user group or non-DMPA contraception user group. The latter group included patients using oral contraceptive pills, transdermal contraceptive patch, intravaginal contraceptive ring, or other forms of hormonal contraception. Following the initial visit, all contraception users (DMPA and non-DMPA) visited the clinic every three- or sixmonths for follow-up. During the follow-up visits, patient weight was recorded and the patient received counseling services by a physician, a licensed psychologist, and/or a nutritionist as deemed appropriate. Data were entered in Microsoft Excel and analyzed using Statistical Analysis Software. The results showed no significant difference in weight gain between groups. We hypothesize that hormonal contraception in adolescent patients, coupled with clinical intervention in form of counseling and regular monitoring, over an extended period (longer than 24 months) is not associated with significant weight gain.
\end{abstract}

Keywords: Adolescent, contraception, clinical counseling, DMPA

Correspondence: Professor Hatim A Omar, MD, FAAP, Director of Adolescent Medicine and Young Parent programs, J422 Kentucky Clinic, Dept. of Pediatrics, Kentucky Children's Hospital, University of Kentucky College of Medicine, Lexington, KY 40536 USA. Tel: 859-323-6426 ext. 311; Fax.859-257-7706; E-mail: haomar2@uky.edu

Submitted: December 15, 2008. Revised: January 20, 2009. Accepted: January 30, 2009.

\section{INTRODUCTION}

In its most recent release, the American Academy of Pediatrics Policy on Contraception and Adolescents continues to recommend provision of hormonal contraception to adolescents by their primary care physicians $(1,2)$. Hormonal contraception is available in various forms including combined oral contraceptive pills, injections, skin patches, subcutaneous implants, and vaginal rings (3). Oral contraceptive pills (OCPs) are the most popular method among adolescents and their protective, therapeutic, and non-contraceptive uses in gynecologic diseases are well documented $(2,4-6)$. Depot Medroxyprogesterone Acetate (DMPA) is the major injectable contraceptive in the United States (4). DMPA injections, similar to OCPs, offer safe, effective, convenient, and reversible birth control choices (7). DMPA injection use is also favorable to use in adolescents who have low compliance rates with OCPs
(8) and are gaining appeal among adolescents, because of their effectiveness (9).

Despite the proven benefits of hormonal contraceptives, a number of controversies have emerged due to their side effects. The OCPs are commonly associated with cardiovascular complications, breakthrough bleeding, and migraine headaches $(2-4,10)$. Injectable contraceptives, on the other hand, are commonly associated with vaginal bleeding $(11,12)$, decreased bone mineral density, and abdominal pain (13). Both oral and injectable contraceptives have been associated with weight gain $(3-5,10,11,13-16)$.

Numerous retrospective and prospective clinical studies conducted in the United States explored the relation between hormonal contraception and weight gain. A 24 month study by Berenson et al (11) of 16-33 year old females found that the odds of weight gain for patients using OCPs or DMPA after 24 months were 
1.19 and 2.27 , respectively, compared with the control group odds of 1.00. In another 12 month study, adolescent Norplant implant users gained more weight than oral contraceptive users ( 8.7 vs. 4.2 pounds respectively) (17). As for DMPA use, a 30-month prospective experimental study of low socioeconomic status adolescent African American patients, weight gain was the most commonly perceived side effect and the primary reason for discontinuation of treatment (18). The finding of weight gain seems to be universal; Austrian high school adolescents who started using the pill at a mean age of $16.0 \pm 0.9$ years noted weight gain as a side effect in addition to an increase in breast size, fatigue, and depression (19).

Contrary to the findings above, other studies showed no significant change in weight with the use of hormonal contraception. A randomized, parallel-group, multicenter study showed that use of OCPs does not substantially affect body weight for most women after 13 cycles of use (20). A study of adolescent and young women using oral contraceptive pills or intra-uterine devices (IUD) as a control group, showed no significant difference between the OCP and IUD groups in initial weight and weight after one year of use (21). A more recent study comparing OCP use to a placebo-controlled group in adolescent subjects showed that changes in body weight and the incidence of estrogen-related side effects in the OCP group after six cycles were not significantly different from placebo-controlled group (22). Due to the numerous controversies in the literature regarding weight gain due to the use of contraceptives, we aim to determine once and for all the effects of contraceptives on weight gain. To this end, we used the patient charts of patients who were on different oral contraceptive use for at least one year, as well as a 'contro:' group who are not using contraceptives.

\section{METHODS}

Data were gathered from the charts of 313 adolescent female patients seen in an outpatient adolescent clinic in Lexington, Kentucky. At the initial visit, all patients were evaluated for risk-taking behavior using the Perkins' Adolescent Risk Screen (PARS) form (1). PARS is a validated screen that assesses a variety of health-related variables, such as Body Mass Index (BMI), nutrition, drug use, and sexual activity, in addition to other biopsychosocial factors (23). Following this assessment, all patients received preventive counseling by a certified psychologist in the clinic.

Hormonal contraception including Depot Medroxyprogesterone Acetate (DMPA) method or non-DMPA methods (including oral contraceptive pill, patch, ring or other forms) was prescribed to a subset of these patients following consultation with the attending physician and the patient. Follow-up visits were scheduled every three months for DMPA contraception users and every 3-6 months for non-DMPA contraception users. During follow-up visits, patient weight was recorded and other screening tests such as HPV (human papillomavirus) screening were conducted. In addition, every patient received counseling by a team composed of a psychologist, social worker, nutritionist, and a nurse practitioner. Data collected from patient charts included demographic information, weight data, HPV screen results, risk taking behavior, and pertinent medical conditions.

Data were entered and BMI was calculated in Microsoft Excel. Data were entered as "missing value" for patients who discontinued hormonal contraception or discontinued visiting the clinic. Statistical Analysis Software (1) was used to analyze the data coded in Excel. The demographic data were analyzed using descriptive statistical measures. A one-way ANOVA statistical test was performed to compare weight change and BMI change in the hormonal contraception user group vs. the control group at the initial visit and every year thereafter. The same analysis was conducted to compare the DMPA vs. non-DMPA groups. The two groups were compared at the end of years $1,2,3,4,5$, and 6 using ANOVA Scheffe's method $P<.05$ was considered statistically significant.

Exclusion criteria: patients who used contraception for less than one year or switched contraception methods in less than one year were also excluded. Using these criteria, the final number of patients in the study was 259 .

\section{RESULTS}

The age range of the patients included in the study was 12-21 years at the beginning of the study. The mean age was $18.1 \pm 2.4$ years. The median value for age was 16.5 years and the mode value was 19.5 years. Of the patients, $98 \%$ reported their status as single, $2 \%$ as married or engaged. In terms of racial distribution, $49 \%$ of the patients were Caucasian, 50\% African American, and $1 \%$ Hispanic. Insurance type was used as an index of socioeconomic status. The vast majority of patients $(72 \%)$ were Medicaid recipients, whereas $21 \%$ were private insurance carriers. The remaining $7 \%$ of patients had no insurance plan and were recipients of financial assistance. With respect to smoking status, most patients $(66 \%)$ were non-smokers whereas $34 \%$ were smokers. 
Table 1: Demographic characteristics of subjects at the beginning of the study $(n=313)$

\begin{tabular}{|c|c|c|c|}
\hline \multirow{2}{*}{ Age } & Mean \pm S.D. & Median & Mode \\
\hline & $15.8 \pm 2.2$ & 16.0 & 16.0 \\
\hline \multirow{2}{*}{ Age Range } & Minimum & Maximum & \\
\hline & 8.5 & 21.0 & \\
\hline \multirow{2}{*}{ Marital Status } & Single & Married & \\
\hline & $97.2 \%$ & $1.8 \%$ & \\
\hline \multirow[t]{2}{*}{ Race } & Caucasian & $\begin{array}{c}\text { African } \\
\text { American }\end{array}$ & Other \\
\hline & $47.9 \%$ & $47.2 \%$ & $4.9 \%$ \\
\hline \multirow{2}{*}{ Insurance Status } & Private & None & Medicaid \\
\hline & $22.4 \%$ & $6.3 \%$ & $71.3 \%$ \\
\hline \multirow{2}{*}{ Smoking Status* } & Yes & No & \\
\hline & $30.6 \%$ & $69.4 \%$ & \\
\hline \multirow{2}{*}{ Substance Abuse } & Yes & No & \\
\hline & $25.1 \%$ & $74.9 \%$ & \\
\hline Contraception group & User & Non-User & \\
\hline Subjects pe group (n) & 215 & 98 & \\
\hline
\end{tabular}

*Other includes Hispanic, Native American, Oriental, and biracial patients.

**The smoking status data not available for $15 \%$ of the patients.

*** Substance abuse data not available for $30 \%$ of the patients.

However, the smoking status was missing for $15 \%$ of all subjects in the study. Regarding substance abuse, $26 \%$ of patients admitted abusing alcohol, drugs, or both, whereas $74 \%$ of patients denied abusing either alcohol or drugs (see table 1).

As previously mentioned, patient weight (in pounds) was recorded at the initial and each follow-up visit. Weight changes per patient were calculated at the end of each year for patients in the contraception user and nonuser (control) groups. A significant difference in the weight changes between the two groups was seen at the end of year $1(p=.03)$. In contrast, no significant differences were observed in the following years (see graph 1).

Subsequently, the BMI calculation was used to compara patients in the contraception user and control groups as described above. No significant difference was found between the two groups at any time point, including year 1 (see graph 2). The height variable was

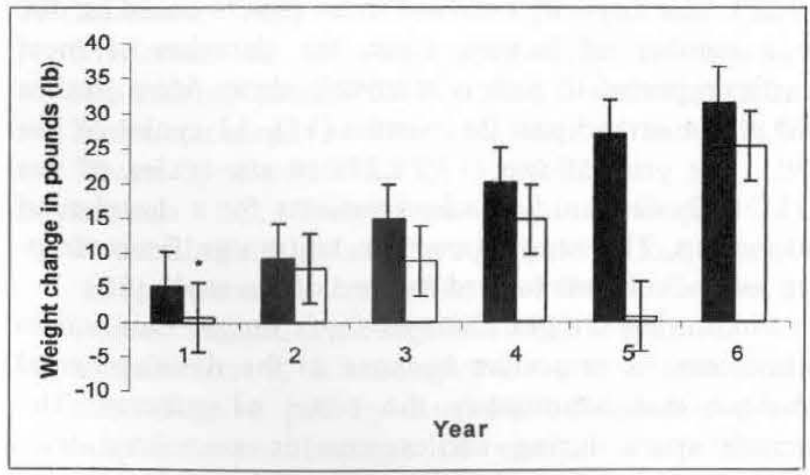

- Birth control user group

$\square$ non-user group

Graph 1: Weight Year Users Controls

pounds per year in contraception $2 \quad 136 \quad 22$

$\begin{array}{llll}\text { user and control groups. } & 3 & 76 & 10\end{array}$

$38 \quad 4$

163

92

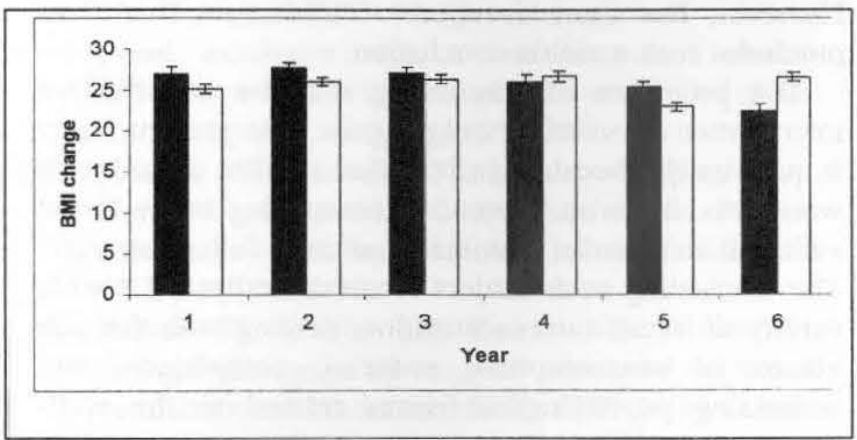

Birth control user group

$\square$ non-user group

\begin{tabular}{lccc} 
& & \multicolumn{2}{c}{ N per group } \\
Graph 2: Body Mass Index (BMI) & Year & Users & Controls \\
change per year in both contra- & 1 & 96 & 34 \\
ception user and control groups. & 2 & 53 & 12 \\
& 3 & 33 & 6 \\
& 4 & 15 & 3 \\
& 5 & 6 & 3 \\
& 6 & 2 & 2
\end{tabular}

not documented for all patients, therefore accounting for decrease in the $n$ value of patients in this graph.

\section{DISCUSSION}

As mentioned previously, the literature is abundant with conflicting results on the association of hormonal contraception with weight change in adolescents $(11,13$ - 
19,22). The disparity between these results could be due to a number of factors. First, the duration of most studies reported to date is relatively short. Most studies did di not extend past 24 months (11), 13 cycles of use (20), one year of use $(17,21,24)$ or six cycles of use (22). Only one study tracked patients for a duration of 30 morths. This study, however, had a significant dropout rate of subjects toward the end of the study (18).

Monitoring weight changes for a longer duration in adolescents is important because of the developmental changes that accompany the onset of puberty. The growth spurt during adolescence is associated with weight and height velocities greater than between the ages of 5 and 10 years (25). This suggests that susceptibility to hormonal contraception may be selectively accentuated in early adolescence, which is associated with the onset of menarche and the use of hormonal contraception. Rather than causing a net weight gain, hormonal contraception could accelerate pubertal development, leading to the final body weight set point that the same subject would have attained eventually if not placed on hormonal contraception. However, the short duration of studies in this field precludes such a viable conclusion.

The provision of counseling may be an effective intervention preventing weight gain. The present study is quite unique because unlike other studies, the subjects were provided with preventive counseling at the initial visit and continuous counseling at each follow-up visit. The counseling each subject received addressed a wide variety of issues such as nutrition, dealing with the side effects of contraception, ensuring compliance, and addressing psychological issues related to the wellbeing of the patient. In contrast, continuous counseling was not reported in other studies investigating the association between hormonal contraception and weight gain (3-5,10,11,13-16). Davies et al (26) recommended that clinicians promote delayed sexual activity and provide counseling to adolescents considering hormonal contraception. The American Association of Pediatrics also continues to recommend preventive, but not continuous counseling to this adolescent population regarding the use of contraceptives (2).

The initial weight before using hormonal contraception may be associated with the degree of weight gain in adolescents. For example, overweight in childhood or excessive body mass increment during pregnancy are risk factors of obesity in the later period of life (27). By analogy, one could hypothesize that overweight adolescents are more susceptible to weight gain induced by hormonal contraception. Risser et al
(24) found that adolescent subjects who gained $>5 \%$ of their baseline weight at 3 months were at high risk $(93 \%)$ of gaining even more weight by one year.

In conclusion, earlier studies on the association of hormonal contraception and weight changes in adolescents reported significant weight gain due to contraceptives. Despite their validity, the duration of such studies, 6-24 months, remains relatively short in the context of adolescent development and thus the study is limited in its interpretive ability. Furthermore, although most studies provided preventive counseling at the initiation of hormonal contraception, none of offered a continuation in psychological counseling services. Our retrospective study is the first to address this question beyond 24 months and to show that weight gain in hormonal contraception users is not significantly different from the control group for up to 72 months. In addition, our study is unique in offering psychological counseling to patients during follow-up visits, which suggests that psychological counseling may be an effective clinical intervention preventing the weight gain traditionally associated with hormonal contraception.

\section{ACKNOWLEDGMENTS}

The authors would like to thank Dr. Heather Bush and Dr. Richard Kryscio for their help with the statistical analysis in this study. The study was supported by the Professional Student Mentored Research Fellowship from the Center for Clinical and Translational Science at University of Kentucky to Abdel Salous.

\section{REFERENCES}

1. Perkins K, Ferrari N, Rosas A, Bessette R, Williams A, Omar H. You won't know unless you ask: the biopsychosocial interview for adolescents. Clin Pediatr (Phila) 1997;36(2):79-86.

2. Felice ME, Feinstein RA, Fisher M, Kaplan DW, Olmedo LF, Rome ES, et al. American Academy of Pediatrics. Committee on Adolescence. Contraception in adolescents. Pediatrics 1999;104(5 Pt 1):1161-6.

3. Blumenthal PD, Edelman A. Hormonal contraception. Obstet Gynecol 2008;1 12(3):670-84

4. Greydanus DE, Patel DR, Rimsza ME. Contraception in the adolescent: an update. Pediatrics 2001;107(3):562-73.

5. Piccinino LJ, Mosher WD. Trends in contraceptive use in the United States: 1982-1995. Fam Plann Perspect 1998;30(1):4-10,46.

6. Rager KM, Omar HA. Hormonal contraception: 
noncontraceptive benefits and medical contraindications. Adolesc Med Clin 2005; 16(3):539-51.

7. Kaunitz AM. Injectable contraception. New and existing options. Obstet Gynecol Clin North Am 2000;27(4):741-80.

8. Cromer BA, Smith RD, Blair JM, Dwyer J, Brown RT. A prospective study of adolescents who choose among levonorgestrel implant (Norplant), medroxyprogesterone acetate (Depo-Provera), or the combined oral contraceptive pill as contraception. Pediatrics 1994;94(5):687-94.

9. Davis AJ. Use of depot medroxyprogesterone acetate contraception in adolescents. J Reprod Med 1996;41(5 Suppl):407-13.

10. Darney PD. OC practice guidelines: minimizing side effects. Int J Fertil Womens Med 1997;Suppl 1:158-69.

11. Berenson $\mathrm{AB}$, Odom SD, Breitkopf CR, Rahman M. Physiologic and psychologic symptoms associated with use of injectable contraception and 20 microg oral contraceptive pills. Am J Obstet Gynecol 2008;199(4):351.e1-12.

12. Rager KM, Fowler A, Omar HA. Successful treatment of depot medroxyprogesterone acetaterelated vaginal bleeding improves continuation rates in adolescents. ScientificWorldJournal 2006; 6: 353-5.

13. Bigrigg A, Evans $M$, Gbolade B, Newton J, Pollard L, Szarewski A, et al. Depo Provera. Position paper on clinical use, effectiveness and side effects. Br J Fam Plann 1999;25(2):69-76.

14. Connor PD, Tavernier LA, Thomas SM, Gates D, Lytton SM. Determining risk between DepoProvera use and increased uterine bleeding in obese and overweight women. J Am Board Fam Pract 2002;15(1):7-10.

15. Frye CA. An overview of oral contraceptives: mechanism of action and clinical use. Neurology 2006;66(6 Suppl 3):S29-36.

16. Khoiny FE. Use of depo-provera in teens. J Pediatr Health Care 1996;10(5):195-201.
17. Berenson AB, Wiemann CM, Rickerr VI, McCombs SL. Contraceptive outcomes among adolescents prescribed Norplant implants versus oral contraceptives after one year of use. Am J Obstet Gynecol 1997;176(3):586-92.

18. Matson SC, Henderson KA, McGrath GJ. Physical findings and symptoms of depot medroxyprogesterone acetate use in adolescent females. J Pediatr Adolesc Gynecol 1997;10(1):18-23.

19. Brunnhuber S, Kirchengast S. Use of the oral contraceptive pill by Austrian adolescents with emphasis on the age of onset, side effects, compliance and lifestyle. Coll Antropol 2002; 26(2):467-75.

20. Burkman RT, Fisher AC, LaGuardia KD. Effects of low-dose oral contraceptives on body weight: results of a randomized study of up to 13 cycles of use. J Reprod Med 2007;52(11):1030-4.

21. Carpenter S, Neinstein LS. Weight gain in adolescent and young adult oral contraceptive users. J Adolesc Health Care 1986;7(5): 342-4.

22. Coney P, Washenik K, Langley RG, DiGiovanna JJ, Harrison DD. Weight change and adverse event incidence with, a low-dose oral contraceptive: two randomized, placebo-controlled trials. Contraception 2001;63(6):297-302.

23. Adams $\mathrm{CD}$, Perkins $\mathrm{KC}$, Lumley V, Hughes $\mathrm{C}$, Burns JJ, Omar HA. Validation of the Perkins Adolescent Risk Screen (PARS). J Adolesc Health 2003;33(6):462-70.

24. Risser WL, Gefter LR, Barratt MS, Risser JM. Weight change in adolescents who used hormonal contraception. J Adolesc Health 1999;24(6):433-6.

25. Tanner J. Growth at adolescence. $2^{\text {nd }}$ ed. Oxford: Blackwell, 1972.

26. Davis AJ. Contraceptive choices: the adolescent years. Dialogues Contracept 1995;4(6):1-2.

27. Ostrowska L, Lech MM, Karczewski J. [Identification of risk factors of obesity in premenopausal women]. Pol Merkur Lekarski 2004; 17(102):6037. [Polish] 